\title{
Pulsatile and Steady-State Pressure Trends in Children: Is the Future Now?
}

\author{
Comment on the Paper by Zachariah and Kovacikova [Pulse 2014;2:57-62] \\ Michael F. O'Rourke \\ St. Vincent's Clinic, University of New South Wales, and Victor Chang Cardiac Research \\ Institute, Darlinghurst, N.S.W., Australia
}

The article by Zachariah and Kovacikova [1] on blood pressure in children sets out the prevailing views on children, which concentrate on the associations of brachial cuff systolic pressure (SP) and diastolic pressure (DP) with obesity [2] and the concern that if elevated levels of SP, DP and obesity track into adulthood, the worldwide epidemic of atherosclerosis will continue in Western countries and worsen in developing nations.

Certainly, SP and DP do increase substantially with age in children so that there are differences between children and adults. In children, there are also different approaches to the definition and diagnosis of hypertension as well as important anomalies. Two different camps are involved, paediatricians and adult physicians, whose approach has been at odds, with little consistency in 'cradle-to-grave' and an uncertain junction at the age of 15-20 years where childhood epidemiological studies [2-4] conclude before adult studies begin [5, 6], with the youngest subject in the Framingham Heart study [5] being 25 years of age. There are few studies that continue from childhood into adulthood [7].

Differences between childhood and adult studies of cuff pressure include the following:

- Need to use cuffs of appropriate size in infants and children; frequent non-compliance with advice on cuff size in children and adults.

- Lack of agreement on whether DP in children should be taken from muffling (phase 4) or disappearance (phase 5) of Korotkoff sounds [8].

- Uncertainty about the accuracy of oscillometric methods to measure SP and DP in children.

- Infrequency of cardiovascular events in children and adolescents, and thus lack of evidence to back any definition of hypertension in children on the basis of events and their reduction with medication.

- In the absence of any evidence on events, hypertension in children and adolescents is defined on the basis of measured values of SP and DP in the upper 5\% (or 10\%) of the normal range in population studies on the basis of age, gender, and height [9]. 
As a consequence of the above, there is confusion in the paediatric community as to the significance of 'high' SP or DP in children and adolescents. Zachariah and Kovacikova [1] refer to relatively high SP as being observed commonly in apparently perfectly normal children and adolescents. In a previous study [10], we have proposed that this can be a normal phenomenon in normal adolescents (especially in tall young males) due to high amplification of the pulse in the upper limb, warranting a description of 'spurious systolic hypertension of youth'. We have pressed this view with respect to isolated systolic hypertension, urging that adolescents with high SP should have the central aortic pressure measured before being branded with the stigma of 'hypertension' and being subject to investigations, therapy, and restrictions in a future career [11]. The European Societies of Hypertension and of Cardiology (ESH and ESC [12]) give credence to this view. In stark contrast, US Guidelines and statements from the American Society of Hypertension (ASH), the American College of Cardiology (ACC), and the American Heart Association (AHA) make no mention of this condition $[2,13,14]$, nor does the 12-page review on hypertension in children and adolescents in the New England Journal of Medicine published in September 2014 by a respected author [15].

Zachariah and Kovacikova [1], writing from Boston, appear justifiably uncomfortable with the approach to hypertension in children and adolescents as it currently exists in the USA. The approach to hypertension in general is based on values for SP and DP obtained by the cuff sphygmomanometer. It is surprising that clinicians, in the nation that pioneered the application of cuff sphygmomanometry to community problems of hypertension as 'the silent killer' [16], exactly one century ago through life insurance studies, still persist in the view that the sphygmomanometer cuff exclusively and alone needs be used to diagnose hypertension. The curious situation arises that an American youth who seeks a career in the US Air Force as a pilot or astronaut can be disqualified from entry on the basis of the century-old instrument (the brachial sphygmomanometer) used exclusively to diagnose a disease - 'hypertension'.

Zachariah and Kovacikova [1] suggest advances that could be made from description of blood pressure values as mean (MP) and pulse pressure (PP), rather than SP and DP, quoting the work of Franklin et al. [17] from the Framingham Heart Study that, for persons over the age of 60 years, PP is the better predictor of cardiovascular outcomes than SP or DP. However, an earlier publication on this study showed that PP in males, while predictive of coronary events in persons over the age of 60 years was inversely related to coronary events under the age of 40 years [18]. Dawber et al. [19] and Kannel et al. [20] from the Framingham study had first called attention to aortic stiffening with age as causing an increase of SP and PP in older humans and had introduced pulse waveform analysis in diagnosing this condition (fig. 1). Their work stimulated the US National Institutes of Health to undertake the Systolic Hypertension in the Elderly Project (SHEP), which confirmed ill effects of elevated SP in persons over 60 years of age and the benefits of treating this with medical therapy in order to reduce the risk of coronary events, stroke, and cardiac failure, irrespective of whether DP was normal or low. SHEP [21] was confirmed by the reanalysis of European [22] and Chinese [23] studies in persons with systolic hypertension over 60 years of age. Isolated systolic hypertension was introduced in 1991 and became the major focus of attention in the treatment of hypertension. We believe that a mistake was made in applying the results of SHEP to persons under the age of 60 years, in many of whom elevated brachial SP was caused not by aortic stiffening [24], but by high amplification of brachial and radial pressure from a normal aortic pressure wave $[10,11,25]$.

The logic of Zachariah and Kovacikova [1] on measuring MP and PP is unfortunately flawed $[10,11,24]$. MP of an invasively recorded pressure wave is usually obtained by mathematical integration over the duration of the wave. It cannot be obtained with any formula such as (MP = DP + 1/3 of PP), since MP depends on the shape of the wave (with quite different results depending on whether the peak of the wave is highly spiked as in children or broadly 
O'Rourke et al.: Pulsatile and Steady-State Pressure Trends in Children: Is the Future Now?

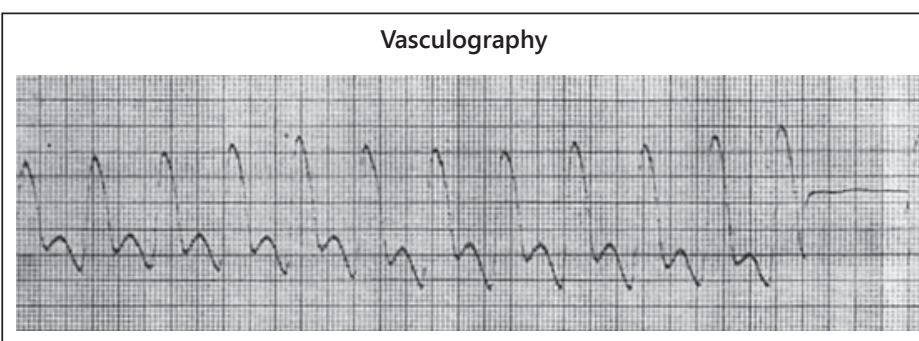

Class I - A distinct incisura is inscribed on the downward slope of the pulse wave.

Fig. 1. Four classes of vasculographs, published by Dawber et al. [19] in the Framingham study, representing low stiffness (top), high stiffness (bottom), and intermediate stiffness (center). For further explanation, see text.

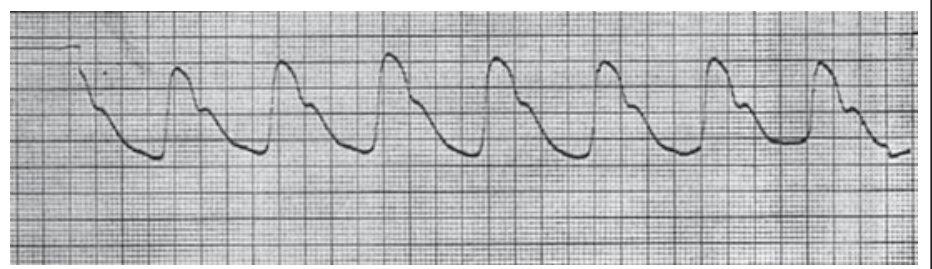

Class II - No incisura develops but the line of descent becomes horizontal.

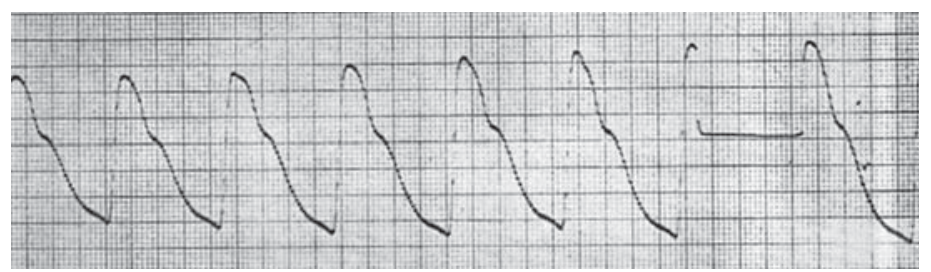

Class III - No notch is present but a well-defined change in the angle of descent is observed.

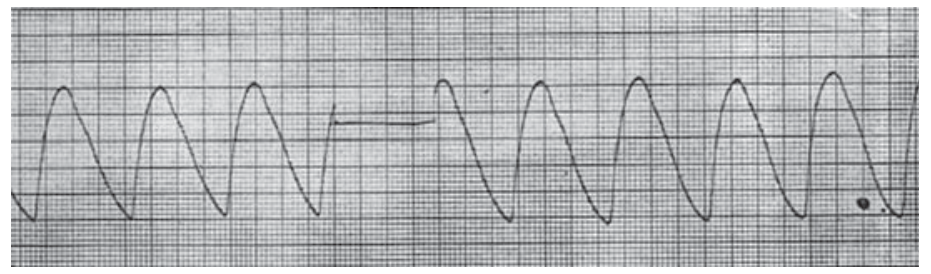

Class IV - No evidence of a notch is seen.

rounded as in elderly persons [26]). The amplitude of the pressure wave is different when taken simultaneously in a peripheral artery, such as the radial or brachial, and in the ascending aorta, whereas MP is almost exactly the same, with an imperceptible drop (less than $1 \mathrm{~mm}$ $\mathrm{Hg}$ ) between the aorta and peripheral artery [27].

The suggestion of using MP and PP could become a reality by using a brachial cuff and oscillometry, where maximal oscillation in the cuff corresponds to the MP in the artery [28], and where proprietary cuff algorithms are used to detect pressures that correspond to SP (peak), and DP (trough) from the oscillometric waveform, not just for the brachial artery (as done now), but for the ascending aorta as well. A number of device companies, including Omron and AtCor Medical, are working towards this goal.

The most promising approach to arterial pressure in childhood, through adolescence, and even into adulthood comes from the consideration of wave reflection in the arterial system as well as peripheral resistance and central aortic stiffness. Ejection of blood from the left ventricle is monophasic, i.e. a single spurt. This generates a similar pressure wave in the 
ascending aorta but is interrupted by wave reflection from the vascular networks of peripheral sites, where low-resistance arteries terminate in high-resistance arterioles [24]. There are more of these positively reflecting peripheral sites in the lower body than in the trunk and upper body, so that wave reflection may take the form of a discrete secondary wave arising from the lower limb, which appears to show damped oscillation throughout diastole around the exponentially declining pressure preceding the next wave, i.e. the next spurt of flow from the left ventricle [19] (fig. 1).

The shape of the pressure wave in an artery depends on its site, the length (height) of the body, and the speed of travel of the pulse along the wall of the arterial tree. Typical wave shapes were shown by the Framingham investigators to represent the stiffness of the arterial tree in adult humans (fig. 1). At one extreme, denoting low stiffness (fig. 1; top panel), the initial systolic peak was early in systole, and a separate positive wave was seen in diastole, denoting return of the pressure wave. Here, the reflected wave was seen separately from the incident wave and returning late from the periphery. At the other extreme (fig. 1; bottom panel), denoting high arterial stiffness, the usual peak was represented by a shoulder on the wave, and the reflected wave, returning early, created a peak in late systole, with no perceptible further fluctuation during diastole. Two intermediate types of wave were described by Kannel et al. [20] and Dawber et al. [19]. In adults, the shape of the wave was associated with the presence of arteriosclerotic disease and future cardiovascular events in the Framingham study $[19,20,24]$, but the results were not decisive and this project was not continued. In even earlier texts, one can see that the pressure waveform with a late systolic peak and exponential decline during diastole was recognised by 19th century sphygmograph pioneers including Marey, Mahomed, and Mackenzie to signify aging, arteriosclerosis, and high blood pressure in adults [24].

Limited data are available on pressure waveforms in children but are beginning to emerge from the ongoing longitudinal studies of 8-year-old children by Celermajer's group [29] in Sydney using the SphygmoCor system. This paper shows evidence of high, wave reflection in both male and female children with amplification of almost $20 \mathrm{~mm} \mathrm{Hg}$ between calculated central aortic and measured radial systolic peaks. In our limited study of children and adolescents [30], we have seen a similarly high amplification of the radial peak above the calculated central aortic peak in children as young as 5 years of age, and with amplification increasing with age, especially in adolescents of 18 years of age, when growth in height stops.

These observations help to explain the values of SP reported in the NHBPEP childhood studies [3]. These showed a progressive increase in SP from the first year of life (85 $\mathrm{mm} \mathrm{Hg}$ ) to $115 \mathrm{~mm} \mathrm{Hg}$ at the age of 17 years. This increase in SP of $30 \mathrm{~mm} \mathrm{Hg}$ in 16 years is greater than seen at any time later in life. Indeed, there is a gap between the age covered by these studies and the major studies in adults, and a plateau in SP appears around this time. The adult studies continue this plateau to around the age of 35 years, whereafter pressure begins again to climb progressively with age.

When data on children and adults are graphed together from the major trials of brachial pressure from males to females, we see a progressive rise in SP for males and females to around the age of 20 years, then a plateau to the age of 35 years, and a secondary slower rise from the age of 40 years [6]. This is likewise seen in the only longitudinal study of brachial cuff pressure following patients from birth to the age of 33 years [7].

When central SP is estimated from the major trials, by reducing SP by the amount of amplification that we have seen in corresponding large studies, we see a near linear rise with age [30], which is quite different to the triphasic increase apparent in the early population studies.

The major points I have tried to make in this Commentary are that values of central aortic pressure (and of PP) in children are much lower, by $10-30 \mathrm{~mm} \mathrm{Hg}$, than when measured at 
the brachial and radial arteries by direct or indirect techniques and that amplification and SP difference is greatest in taller males at the time when full adult height is reached. Differences between the upper limb and the central aorta are attributable to wave reflection and explain the phenomenon of spurious systolic hypertension in tall adolescent males and young adults. This condition should not be considered abnormal or as any type of hypertension as is still done in large parts of the developed world.

Zachariah and Kovacikova [1] have touched a sensitive issue, a veritable Pandora's box, and are to be complimented for bringing this to attention.

\section{References}

1 Zachariah JP, Kovacikova G: Pulsatile and steady-state pressure trends in children: a window into the future? Pulse 2014;2:57-62.

-2 Urbina EM, Williams RV, Alpert BS, Collins RT, Daniels SR, Hayman L, et al; American Heart Association Atherosclerosis, Hypertension, and Obesity in Youth Committee of the Council on Cardiovascular Disease in the Young: Noninvasive assessment of subclinical atherosclerosis in children and adolescents: recommendations for standard assessment for clinical research: a scientific statement from the American Heart Association. Hypertension 2009;54:919-950.

-3 National High Blood Pressure Education Program Working Group on High Blood Pressure in Children and Adolescents: The fourth report on the diagnosis, evaluation, and treatment of high blood pressure in children and adolescents. Pediatrics 2004;114:555-576.

4 Kulaga Z, Litwin M, Grajda A, Kulaga K, Gurzkowska B, Gozdz M, Pan H; OLAF Study Group: Oscillometric blood pressure percentiles for Polish normal-weight school-aged children and adolescents. J Hypertens 2012;30: 1942-1954.

5 Cheng S, Xanthakis V, Sullivan LM, Vasan RS: Blood pressure tracking over the adult life course: patterns and correlates in the Framingham Heart Study. Hypertension 2012;60:1393-1399.

6 McEniery CM, Yasmin, Hall IR, Qasem A, Wilkinson IB, Cockcroft JR; ACCT Investigators: Normal vascular aging: differential effects on wave reflection and aortic pulse wave velocity: the Anglo-Cardiff Collaborative Trial (ACCT). J Am Coll Cardiol 2005;46:1753-1760.

7 Uiterwaal CS, Anthony S, Launer LJ, Witteman JC, Trouwborst AM, Hofman A, Grobbee DE: Birth weight, growth, and blood pressure: an annual follow-up study of children aged 5 through 31 years. Hypertension 1997;30:267-271.

-8 Freedman DS, Foltz JL, Berenson G: Differences between the fourth and fifth Korotkoff phases among children and adolescents. Am J Hypertens 2014;27:1495-1502.

-9 Lurbe E, Cifkova R, Cruickshank JK, Dillon MJ, Ferreira I, Invitti C, et al: Management of high blood pressure in children and adolescents: recommendation of the European Society of Hypertension. J Hypertens 2009;27: 1719-1742.

10 O'Rourke MF, Vlachopoulos C, Graham RM: Spurious systolic hypertension in youth. Vasc Med 2000;5:141145.

11 O’Rourke MF, Adji A: Guidelines on guidelines: focus on isolated systolic hypertension in youth. J Hypertens 2013;31:649-654.

12 Mancia G, Fagard R, Narkiewicz K, Redón J, Zanchetti A, Böhm M, Christiaens T, Cifkova R, De Backer G, Dominiczak A, Galderisi M, Grobbee DE, Jaarsma T, Kirchhof P, Kjeldsen SE, Laurent S, Manolis AJ, Nilsson PM, Ruilope LM, Schmieder RE, Sirnes PA, Sleight P, Viigimaa M, Waeber B, Zannad F; Task Force Members: 2013 ESH/ ESH Guidelines for the management of arterial hypertension: the Task Force for the management of arterial hypertension of the European Society of Hypertension (ESH) and of the European Society of Cardiology (ESC). J Hypertens 2013;31:1281-1357.

13 James PA, Oparil S, Carter BL, Cushman WC, Dennison-Himmelfarb C, Handler J, et al: 2014 evidence-based guideline for the management of high blood pressure in adults: report from the panel members appointed to the Eighth Joint National Committee (JNC 8). JAMA 2014;311:507-520.

14 O'Brien E: End of the Joint National Committee heritage? Hypertension 2014;63:904-906.

15 Ingelfinger J: The child or adolescent with elevated blood pressure. N Engl J Med 2014;370:2316-2325.

16 Fisher JW: The diagnostic value of the sphygmomanometer in examinations for life insurance. JAMA 1914;63: 1752-1754.

17 Franklin SS, Gustin W 4th, Wong ND, Larson MG, Weber MA, Kannel WB, Levy D: Hemodynamic patterns of age-related changes in blood pressure: the Framingham Heart Study. Circulation 1997;96:308-315.

18 Franklin SS, Khan SA, Wong ND, et al: The relation of blood pressure to coronary heart disease risk as a function of age: the Framingham Heart Study. J Am Coll Cardiol 2000;35(suppl A):291A-292A.

19 Dawber TR, Thomas HE Jr, McNamara PM: Characteristics of the dicrotic notch of the arterial pulse wave in coronary heart disease. Angiology 1973;24:244-255. 
-20 Kannel WB, Wolf PA, McGee DL, Dawber TR, McNamara P, Castelli WP: Systolic blood pressure, arterial rigidity, and risk of stroke. The Framingham study. JAMA 1981;245:1225-1229.

-21 SHEP Cooperative Research Group: Prevention of stroke by antihypertensive drug treatment in older persons with isolated systolic hypertension. Final results of the Systolic Hypertension in the Elderly Program (SHEP). JAMA 1991;265:3255-3264.

-22 Staessen JA, Fagard R, Thijs L, Celis H, Arabidze GG, Birkenhäger WH, et al: Randomised double-blind comparison of placebo and active treatment for older patients with isolated systolic hypertension. The Systolic Hypertension in Europe (Syst-Eur) Trial Investigators. Lancet 1997;350:757-764.

23 Liu L, Wang JG, Gong L, Liu G, Staessen JA: Comparison of active treatment and placebo in older Chinese patients with isolated systolic hypertension. Systolic Hypertension in China (Syst-China) Collaborative Group. J Hypertens 1998;16:1823-1829.

24 Nichols WW, O’Rourke MF, Vlachopoulos C: McDonald's Blood Flow in Arteries, ed 6. London, Hodder Arnold, 2011.

-25 Herbert A, Cruickshank JK, Laurent S, Boutouyrie P; Reference Values for Arterial Measurements Collaboration: Establishing reference values for central blood pressure and its amplification in a general healthy population and according to cardiovascular risk factors. Eur Heart J 2014;35:3122-3132.

26 Adji A, O’Rourke MF: Brachial artery tonometry and the Popeye phenomenon: explanation of anomalies in generating central from upper limb pressure waveforms. J Hypertens 2012;30:1540-1551.

-27 Pauca AL, Wallenhaupt SL, Kon ND, Tucker WY: Does radial artery pressure accurately reflect aortic pressure? Chest 1992;102:1193-1198.

28 Oliver G: Studies in Blood Pressure: Physiological and Clinical, ed 3. London, HK Lewis, 1908.

-29 Ayer JG, Harmer JA, Marks GB, Avolio A, Celermajer DS: Central arterial pulse wave augmentation is greater in girls than boys, independent of height. J Hypertens 2010;28:306-313.

30 Adji A, O'Rourke MF, Avolio A: Tracking of central and upper limb systolic pressure over the normal human lifespan. Circulation 2014;130:A12363. 